\title{
Early Health System Experiences with Collaborative Care (CoCM) Billing Codes: a Qualitative Study of Leadership and Support Staff
}

\author{
Andrew D. Carlo, $\mathrm{MD}^{7}$, Andrea Corage Baden, $\mathrm{PhD} \mathrm{MPH}^{7}$, \\ Rachelle L. McCarty, ND MPH' , and Anna D. H. Ratzliff, MD PhD ${ }^{7}$
}

'Department of Psychiatry and Behavioral Sciences, University of Washington School of Medicine, Seattle, WA, USA; ${ }^{2}$ Department of Biobehavioral Nursing and Health Informatics, University of Washington School of Nursing, Seattle, WA, USA.

BACKGROUND: Although collaborative care (CoCM) is an evidence-based and widely adopted model, reimbursement challenges have limited implementation efforts nationwide. In recent years, Medicare and other payers have activated CoCM-specific codes with the primary aim of facilitating financial sustainability.

OBJECTIVE: To investigate and describe the experiences of early adopters and explorers of Medicare's CoCM codes. DESIGN AND PARTICIPANTS: Fifteen interviews were conducted between October 2017 and May 2018 with 25 respondents representing 12 health care organizations and 2 payers. Respondents included dually boarded medicine/psychiatry physicians, psychiatrists, primary care physicians (PCPs), psychologists, a registered nurse, administrative staff, and billing staff.

APPROACH: A semi-structured interview guide was used to address health care organization characteristics, CoCM services, patient consent, CoCM operational components, and CoCM billing processes. All interviews were recorded, transcribed, coded, and analyzed using a content analysis approach conducted jointly by the research team.

KEY RESULTS: Successful billing required buy-in from key, interdisciplinary stakeholders. In planning for CoCM billing implementation, several organizations hired licensed clinical social workers (LICSWs) as behavioral health care managers to maximize billing flexibility. Respondents reported a number of consent-related difficulties, but these were not primary barriers. Workflow changes required for billing the CoCM codes (e.g., tracking cumulative treatment minutes, once-monthly code entry) were described as arduous, but also stimulated creative solutions. Since CoCM codes incorporate the work of the psychiatric consultant into one payment to primary care, organizations employed strategies such as inter-departmental ledger transfers. When challenges arose from variations in the local payer mix, some organizations billed CoCM codes exclusively, while others elected to use a mixture of CoCM and traditional fee-for-service (FFS) codes. For most organizations, it was important to demonstrate financial sustainability from the CoCM codes.

\footnotetext{
Prior Presentations An earlier version of the manuscript was presented at the annual meeting of the American Academy of Consultation-Liaison Psychiatry (ACLP) in Orlando, FL, on 16 November 2018.
}

Received December 14, 2018

Revised April 17, 2019

Accepted June 13, 2019

Published online July 31, 2019
CONCLUSIONS: With deliberate planning, persistence, and widespread organizational buy-in, successful utilization of newly available FFS CoCM billing codes is achievable.

KEY WORDS: mental health; payment policy; integrated care; collaborative care; qualitative research.

J Gen Intern Med 34(10):2150-8

DOI: $10.1007 / \mathrm{s} 11606-019-05195-0$

(C) Society of General Internal Medicine 2019

\section{INTRODUCTION}

Collaborative care $(\mathrm{CoCM})$ is an evidence-based, integrated model for the treatment of common mental health conditions in the medical setting ${ }^{1,2}$. In CoCM, the primary medical provider works closely with a behavioral health care manager who provides assessments, brief psychosocial interventions, and medication management guidance, all with support from a designated psychiatric consultant ${ }^{2}$ (Table 1). Other key CoCM components include treatment to evidence-based targets and the systematic use of a patient registry. The efficacy of CoCM has been demonstrated by more than 80 randomized controlled trials $(\mathrm{RCTs})^{3}$ and its core principles have been applied to the treatment of numerous mental health conditions ${ }^{4-9}$ in a variety of settings ${ }^{9,}{ }^{10}$. However, its non-traditional, teambased workflow (including an emphasis on the time between face-to-face visits) has made reimbursement a major challenge ${ }^{2}$. In many cases, uncertainty about CoCM service costs and the lack of a clear pathway for reimbursement have made the model appear financially untenable ${ }^{11}$.

In response, the Centers for Medicare and Medicaid Services (CMS) ${ }^{12}$ introduced the opportunity for fee-forservice (FFS) reimbursement of CoCM for Medicare beneficiaries in 2017 with three temporary G-codes: G0502, G0503, and $\mathrm{G} 0504^{13}$. In 2018, these G-codes were transitioned to largely identical CPT codes 99492, 99493, and $99494^{2,14,15}$ (Table 2). As with Medicare's 2015initiated, time-based Chronic Care Management (CCM) $\operatorname{codes}^{16,17}$, CoCM codes are billed by a medical practitioner to reimburse for the cumulative time that the $\mathrm{CoCM}$ team spends managing patients over the course of a calendar month. Although the CoCM billing practitioner is 
Table 1 Detailed CoCM Team Member Roles

\begin{tabular}{|c|c|}
\hline $\begin{array}{l}\text { Treating (Billing) } \\
\text { Practitioner* }\end{array}$ & $\begin{array}{l}\text { - Directs the behavioral health care manager } \\
\text { and clinical staff } \\
\text { - Oversees the beneficiary's care, including } \\
\text { prescribing medications }\end{array}$ \\
\hline $\begin{array}{l}\text { Behavioral Health Care } \\
\text { Manager }\end{array}$ & $\begin{array}{l}\text { - Provides the following with systematic } \\
\text { support from a psychiatric consultant: } \\
\text { - Assessment and care management services, } \\
\text { including the administration of validated } \\
\text { rating scales } \\
\text { - Behavioral health care planning in relation } \\
\text { to behavioral or psychiatric health problems, } \\
\text { including revision for patients who are not } \\
\text { progressing or whose status changes } \\
\text { - Brief psychosocial interventions } \\
\text { - Maintenance of the registry }\end{array}$ \\
\hline Psychiatric Consultant & $\begin{array}{l}\text { - Participates in regular review of clinical } \\
\text { status of patients receiving CoCM service } \\
\text { - Advises the team regarding diagnosis } \\
\text { - Indicates options for resolving issues with } \\
\text { beneficiary adherence and tolerance of } \\
\text { behavioral health treatment } \\
\text { - Makes adjustments to behavioral health } \\
\text { treatment plan for beneficiaries who are not } \\
\text { progressing } \\
\text { - Manages any negative interactions between } \\
\text { beneficiaries' behavioral health and medical } \\
\text { treatments. }\end{array}$ \\
\hline
\end{tabular}

The above table was adapted from the Medicare Learning Network $(M L N)$ "Behavioral Integration Services Fact Sheet",

*The Treating (Billing) Practitioner is often the primary care physician

typically the primary care provider, specialists (e.g., cardiologists, nephrologists) are also eligible. Practices billing the codes must inform patients of possible co-insurance, demonstrate their delivery of evidence-based CoCM, and meet all other requirements outlined by CMS (Table 3).

Despite extensive efforts by health care leaders to raise awareness of CoCM $\operatorname{codes}^{11,13}$, the authors know of few adopting organizations to date. In a 2017 qualitative study, O'Malley and colleagues found that only about $4.5 \%$ of eligible primary care providers (PCPs) billed Medicare for the CCM service during the first 15 months of reimbursement ${ }^{17}$. Given notable clinical and billing similarities with CCM, CoCM is likely to follow a comparable uptake pattern. At present, however, the lack of

Table 2 Medicare CoCM Services Codes

\begin{tabular}{ll}
\hline \hline $\begin{array}{l}\text { CPT } \\
\text { Code }\end{array}$ & Description \\
\hline $\mathbf{9 9 4 9 2}$ & $\begin{array}{l}\text { Initial month of CoCM } \\
\text { - First } 70 \text { minutes in the first calendar month of CoCM } \\
\text { treatment activities }\end{array}$ \\
$\mathbf{9 9 4 9 3}$ & $\begin{array}{l}\text { Subsequent month of CoCM } \\
\text { - First } 60 \text { minutes in a subsequent month of CoCM } \\
\text { treatment activities }\end{array}$ \\
$\mathbf{9 9 4 9 4}$ & $\begin{array}{l}\text { Initial or subsequent psychiatric CoCM } \\
\text { - Each additional 30 minutes in a calendar month of } \\
\text { behavioral health care manager activities } \\
\text { (may be billed up to twice per patient per month) }\end{array}$ \\
\hline
\end{tabular}

The above table was adapted from the Medicare Learning Network $(M L N)$ "Behavioral Integration Services Fact Sheet", sufficient Medicare claims data for CoCM codes makes it challenging to effectively quantify their usage to date.

Using data obtained from qualitative, semi-structured interviews with health care organization representatives and payers, the authors present the first known study describing the experiences of early adopters and explorers of Medicare's CoCM codes. It is hoped that these results will assist current and future practices with $\mathrm{CoCM}$ reimbursement and enable payers (including Medicare) to optimize reimbursement for behavioral health integration services.

\section{METHODS}

\section{Sample Selection}

Leveraging the professional contacts of the University of Washington's AIMS Center ${ }^{18}$ and a nationwide network of CoCM stakeholders, the authors employed a purposeful sampling strategy to access a regionally diverse selection of U.S. health care organizations that were either considering or currently billing for CoCM services using Medicare's billing codes. On the recommendations of our contacts, the study sample was expanded to include payers that were reimbursing for the codes.

\section{Data Collection}

From October 2017 to May 2018, the primary investigator (ADC) conducted 1-h individual or group interviews with individuals at organizations nationwide that were knowledgeable about CoCM billing. Telephone or video conference interviews were facilitated by a semi-structured interview guide adapted from O'Malley and colleagues' previously mentioned study on CCM Medicare billing. ${ }^{17}$ The CoCM study interview guide addressed five core categories: health care organization characteristics, CoCM services (e.g., implementation, eligible diagnosis, staffing), patient consent, CoCM operational components (e.g., registry, time accrual, electronic health record (EHR)), and CoCM billing processes. All interviews were facilitated by a psychiatrist skilled in interviewing techniques and were audio-recorded and professionally transcribed. No honorarium was provided for study participation. This protocol was reviewed and granted exemption by the University of Washington Human Subjects Division (00003585).

\section{Analysis}

A content analysis approach ${ }^{19}$ was used to systematically summarize respondent responses. Concurrent with data collection, the analysis was conducted collaboratively by the four-author interdisciplinary team comprised of two psychiatrists with expertise in CoCM and billing, a physician-scientist experienced in health workforce research, and a qualitative medical sociologist. All team members reviewed the initial transcripts, meeting 
Table 3 Core Components of CoCM Billing

\begin{tabular}{ll}
\hline \hline Required CoCM Team & - Treating (Billing) Practitioner, \\
Members & Behavioral Health Care Manager, \\
& Psychiatric Consultant, and Beneficiary \\
& (Patient)
\end{tabular}

Eligible Conditions

- Any mental health, behavioral health, or psychiatric condition being treated by the billing practitioner

Consent

Measurement-Based Treatment to Target

Other Service

Components

Time Accrual

- Prior to commencement of $\mathrm{CoCM}$, the beneficiary must give the billing practitioner permission to consult with relevant specialists, which includes the psychiatric consultant

- The billing practitioner must inform the beneficiary that cost sharing may apply

- Consent may be verbal (written consent is not required), but must be clearly documented in the medical record

- Proactive, systematic follow-up by care manager using validated rating scales and

- Initial assessment by the billing practitioner and behavioral health care manager

- Administration of validated rating scales - Billing practitioner and behavioral health care manager work jointly with the patient to create a treatment plan (may include psychotherapy, medications and other evidence-based treatments) - Assessment of treatment adherence, tolerability, and clinical response using validated rating scales

- Possible provision of brief, evidence-based psychosocial interventions

- Regular case load review with a psychiatric consultant - Treatment plan revision for patients whose condition is not improving adequately

- The specific codes billed for an the CoCM registry individual patient are determined monthly by the total minutes of service provided jointly by all members of the CoCM team over the course of that calendar month - Behavioral health care manager time spent in strictly administrative or clerical duties is not counted towards the accrued CoCM time

The above table was adapted from the Medicare Learning Network $(M L N)$ "Behavioral Integration Services Fact Sheet",12

regularly to discuss data and identify relevant text within the documents. The selected text was labeled with codes using the interview guide's core categories as the overarching coding scheme, with codes continually added or modified to capture emergent ideas.

Once major categories and codes were determined, matrix display tables ${ }^{20}$ were created in Microsoft Excel. This tabular format organizes data by code and case for comparative analysis within and across organizations, enabling observation of similarities, differences, and other key patterns. Two members (ADC, RLM) coded the remaining transcripts and entered data into the matrix tables ${ }^{20}$. Team members then summarized the range of CoCM billing experiences reported by respondents based on matrix data. All tables and summaries were reviewed in team consultation. Discrepancies were resolved through consensus.

\section{RESULTS}

\section{Sample Description}

This investigation included 15 in-depth interviews and a total of 25 respondents (Table 4). Two additional health care organizations declined from participating and a third did not respond to our interview request.

Respondents represented 12 health care organizations and 2 payers located in urban, geographically diverse areas. Of the 12 health care organizations, which were all large, multi-clinic systems, 8 were academically affiliated and the others were community-based. The number of clinics offering CoCM services within each health care organization varied considerably, as did the size of active patient panels and the number of staff members involved in providing the service. At the time of interview, 5 of the investigation's 12 organizations were actively billing Medicare for CoCM. The remaining 7 were in various phases of billing initiation, ranging from anticipating launch within the year to deferring efforts for at least the near future. Four had prior experience with Medicare's CCM codes. Detailed characteristics of the organizations can be found in Table 5 .

Table 4 Characteristics of Respondents from Health Care Organizations and Payers $(n=25)$

\begin{tabular}{|c|c|c|}
\hline $\begin{array}{l}\text { Respondent } \\
\text { characteristic }\end{array}$ & Category & Number \\
\hline \multirow[t]{8}{*}{$\begin{array}{l}\text { Respondent role in } \\
\text { organization }\end{array}$} & $\begin{array}{l}\text { Behavioral Health Medical } \\
\text { Director } *^{\dagger}\end{array}$ & 11 \\
\hline & Other BH Medical or & 6 \\
\hline & $\begin{array}{l}\text { Organization-Level } \\
\text { Leadership }\end{array}$ & \\
\hline & CoCM Psychiatric & 4 \\
\hline & Consultant* & \\
\hline & Behavioral Health Clinical & 2 \\
\hline & & \\
\hline & Billing Department Staff & 2 \\
\hline \multirow[t]{8}{*}{$\begin{array}{l}\text { Respondent training } \\
\text { background, license, or } \\
\text { credential }\end{array}$} & $\begin{array}{l}\text { MD/DO - Internal Medicine/ } \\
\text { Family Medicine and } \\
\text { Psychiatry (double-boarded) }\end{array}$ & 4 \\
\hline & MD/DO - Psychiatry & 10 \\
\hline & $\begin{array}{l}\text { MD/DO - Internal Medicine } \\
\text { or Family Medicine }\end{array}$ & 2 \\
\hline & $\begin{array}{l}\mathrm{PhD} \text { (Psychologist) or PsyD } \\
\text { (Doctor of Psychology) }\end{array}$ & 2 \\
\hline & $\begin{array}{l}\text { MA (Psychology or } \\
\text { Social Work) }\end{array}$ & 2 \\
\hline & MPH (Public Health) & 1 \\
\hline & RN (Registered Nurse) & 1 \\
\hline & $\begin{array}{l}\text { Other (Business or } \\
\text { Accounting) }\end{array}$ & 3 \\
\hline
\end{tabular}

*All CoCM Psychiatric Consultants and 2 Behavioral Health Medical Directors also held teaching hospital leadership or faculty positions tTwo Behavioral Health Medical Directors also served as CoCM Psychiatric Consultants 
Table 5 Characteristics of Health Care Organizations $(n=12)$

\begin{tabular}{|c|c|c|}
\hline Organization characteristic & Category & Number \\
\hline $\begin{array}{l}\text { Billing Medicare for CoCM at the } \\
\text { time of interview } \\
\text { Number of unique clinics offering } \\
\text { CoCM within organizations }\end{array}$ & $\begin{array}{l}\text { Yes } \\
\text { No } \\
1 \text { clinic } \\
2-5 \text { clinics } \\
5-10 \text { clinics } \\
10+\text { clinics }\end{array}$ & $\begin{array}{l}5 \\
7 \\
2 \\
4 \\
4 \\
2\end{array}$ \\
\hline $\begin{array}{l}\text { Within billing organizations } \\
(n=5) \text {, number of clinics } \\
\text { billing for CoCM } \\
\text { Active CoCM patient panel }\end{array}$ & $\begin{array}{l}1-2 \text { clinics } \\
3-5 \text { clinics } \\
4+\text { clinics } \\
\text { Unknown or fluid } \\
0-99 \text { patients } \\
100+\text { patients }\end{array}$ & $\begin{array}{l}2 \\
1 \\
2 \\
6 \\
3 \\
3\end{array}$ \\
\hline $\begin{array}{l}\text { Number of primary care providers } \\
\text { (M.D., D.O., N.P., P.A.) involved } \\
\text { in providing CoCM services }\end{array}$ & $\begin{array}{l}0-10 \text { providers } \\
11-50 \text { providers } \\
51+\text { providers } \\
\text { Unknown }\end{array}$ & $\begin{array}{l}1 \\
5 \\
3 \\
3\end{array}$ \\
\hline $\begin{array}{l}\text { Full-time equivalent (FTE) of } \\
\text { psychiatric consultant time } \\
\text { devoted specifically to } \\
\text { CoCM services }\end{array}$ & $\begin{array}{l}0-1.0 \text { FTE } \\
1.1-2 \text { FTE } \\
2.1+\text { FTE } \\
\text { Unknown }\end{array}$ & $\begin{array}{l}4 \\
5 \\
2 \\
1\end{array}$ \\
\hline $\begin{array}{l}\text { Number of care managers devoted } \\
\text { to CoCM services }\end{array}$ & $\begin{array}{l}1 \text { care manager } \\
2-5 \text { care managers } \\
6-10 \text { care managers } \\
10+\text { care managers } \\
\text { Unknown }\end{array}$ & $\begin{array}{l}3 \\
4 \\
2 \\
2 \\
1\end{array}$ \\
\hline $\begin{array}{l}\text { Geographic area of organization } \\
\text { within the USA }\end{array}$ & $\begin{array}{l}\text { Northeast } \\
\text { South } \\
\text { Midwest } \\
\text { West }\end{array}$ & $\begin{array}{l}4 \\
4 \\
3 \\
1\end{array}$ \\
\hline Affiliation of organizations & $\begin{array}{l}\text { Academic or } \\
\text { academically } \\
\text { affiliated } \\
\text { Non-academic }\end{array}$ & 8 \\
\hline $\begin{array}{l}\text { Prior organization experience with } \\
\text { CCM }\end{array}$ & $\begin{array}{l}\text { Yes } \\
\text { No } \\
\text { Unknown }\end{array}$ & $\begin{array}{l}5 \\
4 \\
3\end{array}$ \\
\hline
\end{tabular}

\section{Health Care Organization Perspectives}

The following sections highlight findings from interviews with the 12 participating health care organizations about contextual factors influencing billing implementation, core CoCM billing components, and financial sustainability. Data from organizations currently billing Medicare (referred to as "billers") are contrasted with those not yet billing (referred to as "non-billers").

\section{Internal and External Contextual Factors} Buy-in from Key Stakeholders for CoCM Billing. Medicare $\mathrm{CoCM}$ codes require significant adjustments to established billing workflows and processes. Consequently, buy-in from stakeholders within (and occasionally outside) the organizations was of paramount importance. Respondents reported engaging key individuals early in the planning process and working collaboratively across units and departments. As one respondent noted:

It was a big, big lift from a lot of different people, from the [EHR name] folks, to the registry, the analytic folks; it was a big project. [BH Medical Director, Physician (Medicine/Psychiatry), Biller]

Among organization leadership, the need to cover costs of the non-reimbursable services associated with CoCM served as the impetus for CoCM billing. Goals of increasing mental and behavioral health capacity were additional billing promoters, as were mission and values (e.g., addressing underserved population needs).

Differences in primary motivators were observed between billers and non-billers. Billing organizations were more likely to have implemented CoCM after (or in response to) the release of Medicare codes. In contrast, most non-billing organizations implemented CoCM with the assistance of alternative funding prior to Medicare code release. Loss of this alternative funding could incentivize organizations to more actively pursue Medicare billing, as one respondent explained:

We have a ... grant, that's ending ... and actually, for the purposes of collaborative care staffing, it has ended ... which is why ... I think people are much more interested now, in trying to figure out where we can tap into all the other payment sources... [BH Medical Director, Physician (Psychiatry), Non-biller]

Buy-in from compliance officers was also critical and, as one organization experienced, could bring CoCM billing implementation efforts to a halt if certain ethical and legal issues were left unacknowledged. Some such concerns included Medicarespecific cost sharing, variable CPT code adoption by other payers, procedural issues regarding proper coding, and sufficiency of CoCM clinical documentation. Buy-in discussions with billing and information technology (IT) staff were important as well, and concentrated on the technological infrastructure for time accrual, code entry, and medical record interoperability or integration.

Multiple organizations noted the significance of obtaining buy-in from PCPs and mental health clinicians. Respondents reported that PCPs were most concerned about being asked to obtain consent and discuss cost sharing with patients (despite sharing the service responsibilities with behavioral health staff). For behavioral health care managers, the focus of buy-in discussions was on the process of time accrual, clinical documentation (in both the EHR and registry), and billing code entry.

When discussing the commercial insurance space, respondents reported confusion about the impact of behavioral health benefit carve-outs on eligibility for CoCM reimbursement, given that the codes are entered in the PCP's name, but the service is categorized as behavioral health. One organization felt that CoCM codes billed by primary care could circumvent network restrictions imposed by behavioral carve-outs and increase access to mental health services. Another had a different interpretation, reporting that siloed billing and credentialing resulting from carve-outs could deleteriously complicate reimbursement of integrated care models like CoCM. 
Finally, several respondents reported efforts to secure buyin from stakeholders beyond their health care organizations, most notably with non-Medicare payers, by promoting CoCM's value and long-term cost savings in medical and behavioral health service lines. One health care organization even advocated at the state level using similar arguments.

Selection of Care Team in the Context of CoCM Billing. Under the Medicare rule, organizations billing CoCM codes must have a behavioral health care manager and psychiatric consultant working in collaboration with a treating practitioner, although specific profession types or licensure requirements for these roles have not been stipulated ${ }^{21}$. Several organizations, however, reported purposely reconfiguring their staff in preparation for CoCM billing to allow for the flexible use of other traditional FFS codes that have more specific provider-level restrictions. Most commonly, LICSWs were preferentially hired for their ability to bill psychotherapy codes that are unavailable to RNs and unlicensed social workers. As one organization explained:

...In the other clinics they're all staffed by LICSWs because of the flexibility in being able to bill both collaborative care coding and CPT coding [FFS] psychotherapy. [Organization-Level Leadership, Physician (Psychiatry), Biller]

Conversely, one organization that was unable to hire an eligible billing clinician for traditional FFS codes reported that CoCM codes were especially helpful in moving toward financial sustainability.

Payer Mix and Availability of CoCM Reimbursement from Different Payers. Organization-level payer mix had a significant impact on the CoCM billing strategies of participating sites. While the opportunity for Medicare $\mathrm{CoCM}$ reimbursement was consistent nationwide, the Medicaid and commercial landscapes varied regionally. Depending on the specific patient's payer and the credentials of the care manager, organizations had different approaches. Billing organizations either (1) used CoCM codes for both Medicare and commercial payers or (2) billed a mixture of CoCM codes for Medicare beneficiaries and traditional FFS codes for patients of other non-reimbursing payers. Though not billing Medicare CoCM codes, several non-billing clinics used traditional FFS codes for any billable services delivered as part of CoCM. In some cases, billing differentially by payer generated ethical and legal conundrums for organizations:

...it does feel a little unsettling to have some people have to pay a co-insurance, and then everybody else gets it for free because their insurance doesn't recognize it as a service. [Organization-Level Leadership, Clinical Psychologist, Non-biller]

In response to this concern, one organization stated that individual clinics newer to the CoCM service were being prioritized for billing to minimize the number of long-standing individual patients that had to transition to cost sharing.

Despite having a variety of possible billing strategies, all organizations reported providing $\mathrm{CoCM}$ services to beneficiaries for whom they would not be reimbursed. Some elected to accept the financial loss on these patients (as a result of their strong belief in offering the service), while others referred these patients to other service lines (e.g., specialty mental health care). One health care organization described their acceptance of the financial loss:

...we've used general assessment codes and sort of eaten the costs of the other piece of collaborative care...we treated everybody the same way, except in terms of billing. Because people with Medicaid or no insurance or other insurances, there wasn't a billing mechanism for that. So, you just bill what we currently could, and there is no reimbursement for the other pieces. [BH Medical Director, Physician (Psychiatry), Biller]

Primary reasons non-billers avoided the codes included access to funding from alternative sources (e.g., grants) and poor CoCM service code coverage, typically due to insufficient involvement of commercial payers in the region.

\section{CoCM Billing Components} Attainment and Documentation of Patient Consent for CoCM. Medicare regulation stipulates that patients must be informed of possible cost sharing and provide consent for the team to speak with relevant specialists (including psychiatric consultants) prior to the commencement of CoCM services. This process may be verbal and must be clearly documented in the medical record. Some organizations reported that consent was performed by the PCP, while others mentioned that it was conducted by a different team member (although CMS has stipulated that it must be performed by the treating practitioner ${ }^{12}$ ). Consent was occasionally experienced as a point of contention for PCPs, mostly due to discomfort discussing financial terms or concern about how long it would take:

...we had to involve our providers because we're required to have the providers actually gain their consent. And we dealt with a decent amount of pushback really, about providers having to consent patients and tell them that they might have to pay for the service. $[\mathrm{BH}$ Medical Director, Physician (Psychiatry), Non-biller] 
Organizations also reported that, on occasion, patients had expressed confusion when contacted by the care manager to schedule an intake visit because they had not fully understood $\mathrm{CoCM}$ from the consent process. In response, several organizations (including billers and non-billers) used guidelines or a formal script to ensure that required information was conveyed to patients. Further, most billers and one non-biller reported that an EHR template or shortcut had been created (or was planned) to facilitate documentation of consent.

Tracking Time Accrual, EHR Integration with CoCM Registry, and Billing/Revenue Flow. The organizational transition to billing CoCM codes requires substantial workflow adjustments for billing staff, administrators, care managers, and clinicians. One such adjustment is that all team members must keep track of the time spent caring for a patient over the course of a calendar month, instead of billing at the time of service. This major shift necessitates the development of new strategies and infrastructure for patient-level data accrual and maintenance. Although three participating organizations had optimized their EHR and registry for this purpose, two successful CoCM code billers did not have EHR-registry integration at the time of interview. This demonstrates that a lack of IT integration or interoperability is not an insurmountable barrier to billing CoCM codes.

Of those health care organizations that had achieved EHRregistry integration, some reported a perceived increase in efficiency by allowing documentation (including time accrual) to occur in one place. Others highlighted their capacity to efficiently document consent, identify eligible patients, or run reports of aggregated data. At the time of interview, however, no organization had succeeded in fully automating the process of billing accrued encounter-based time directly from data entered into an integrated EHR-registry. Even with integration or interoperability, the time accrual and code entry tasks were still often left to the care manager and billing department, which occasionally became a source of contention. One respondent noted:

...we're trying to work on that...the care managers complain about the registry a lot. It takes a lot of their time. It decreases the amount of time that they spend with patients... [Organization-Level Leadership, Physician (Psychiatry), Biller]

The in-house IT teams were vital for organizations with successful EHR-registry integration. Those that had not yet integrated IT systems, but sought to do so, were challenged by competing EHR modification priorities, a reluctance to disrupt ongoing systems, a lack of IT financial support, or general technical difficulties.

CoCM billing challenges also arose directly from the atypical structure of the service, which is delivered in the primary care setting, billed in the name of the primary care provider, and rendered partially by behavioral health providers. Mechanisms are frequently unavailable for reimbursement dollars paid to the primary care department (incorporating the work of the psychiatric consultant) to be directly used to compensate the psychiatric consultant or care managers. In this way, CoCM codes expose how siloed departmental revenue acquisition can pose additional difficulties for the financing of integrated care. According to one respondent:

I guess from the billing perspective...you can bill the $\mathrm{G}$ $[\mathrm{CoCM}]$ codes but then where does my salary come from...? How does that money trickle down to pay the people who need to be paid? [Organization-Level Leadership, Physician (Psychiatry), Non-biller]

One organization initially utilized ledger transfers to move reimbursement revenue across departments but ultimately found this to be burdensome. Instead, it developed a virtual integrated care clinic to solve the problem:

...this idea of building a virtual clinic in the computer system. It's going to be called behavioral health integration, and it will be primary care clinic where primary care doctors can bill, but the revenue will come to the psychiatry department. This new virtual office, we have to build it in [EHR Name] ... requires a huge [EHR Name] build. [Organization-Level Leadership, Physician (Psychiatry), Biller]

Despite the virtual clinic's effectiveness in resolving ledger transfer obstacles, it simultaneously created credentialing and insurance paneling challenges for providers in both departments.

Finally, both billing and non-billing organizations noted apprehensions about loss of revenue from months in which accrued time did not meet stipulated thresholds and, more generally, what constituted billable time. Despite the clinical and billing similarities between CoCM and CCM, an organizational history of the latter did not appear to mitigate these or other billing-related concerns.

\section{Impact of CoCM Codes on Financial Sustainability}

Financial sustainability was a major factor for several billing organizations that aimed to expand mental health services. Both billing and non-billing organizations mentioned collecting CoCM cost data to assess the feasibility of maintenance or expansion. For some non-billing organizations, breaking even on salaries and generally covering program costs were considered indicators of success. A few health care organizations also noted that anticipating more 
payers to activate CoCM codes was a facilitator in moving toward billing implementation:

Again, we're only looking at the Medicare codes... when we get to being able to do it for all payers, we might be able to measure...our...costs...versus what we get reimbursed, it might be worth it [BH Medical Director, Physician (Psychiatry), Biller]

\section{Perspectives from Payers}

The authors conducted additional interviews with two payers that were already reimbursing for CoCM. Both payers commented extensively on their confidence in the evidencebased CoCM service, appreciating that it improves access, increases behavioral health clinical support for PCPs, and is a high-value investment. Payers hoped that activating the codes would be an effective way to incentivize practices to implement the CoCM service. According to one respondent:

For the plan, it's in our best interest [to implement $\mathrm{CoCM}$ ], because the overall medical spend is cheaper...We can actually give people lesser increases of their premium... We have happier patients that are healthier... Whereas if you don't keep your prices down, then they...go somewhere else. [BH Medical Director, Physician (Psychiatry), Payer]

Additionally, payers reported that their confidence in the CoCM service was highly dependent on clinics and providers closely adhering to the service's gold standard guidelines. According to one respondent:

...essentially, in order to get the...reimbursement for collaborative care, we need to be confident that they are using the collaborative care model... and not just saying, 'I'm doing collaborative care.' [BH Medical Director, Public Health Practitioner (MPH), Payer]

As with the health care delivery organizations, payers experienced challenges with internal buy-in to activate CoCM code reimbursement within their own organizations. This was attributed to the composition of the insurance workforce, which often includes non-clinical staff members with little mental health experience. As one respondent explained:

...the political push to be able to...bring your stakeholders... along with your line of thinking. That takes a learning curve to break it down...for all of those different stakeholders, administrators, people that aren't physicians, or medically oriented [BH Medical Director, Physician (Psychiatry), Payer]

Unique to their vantage point, payers noted challenges associated with informing practices that CoCM codes were activated and billable. They struggled to find effective means to deliver the message to clinicians and health care leaders beyond existing virtual forums, meetings, and email threads. This sentiment was generally consistent with that of health care organization representatives, many of whom endorsed difficulties in determining which local and regional payers were reimbursing for $\mathrm{CoCM}$.

\section{DISCUSSION}

Although implementation of newly available CoCM billing codes poses numerous operational challenges, the results of this investigation demonstrate that five early adopters have used the Medicare CoCM codes successfully. The remaining seven participating health care organizations were in various phases of considering or initiating billing. Successful organizations secured institutional buy-in from key stakeholders, clearly outlined CoCM billing and service populations, defined workflows for time accrual, and instituted processes for code entry and consent. These attributes were often not easy to achieve, with even successfully billing organizations readily acknowledging them as challenges. Table 6 provides a summary of these key findings and the authors' proposed strategies to help overcome common barriers.

Data from this investigation had notable parallels to a recent qualitative study that assessed early experiences of providers, practices, and professional societies with Chronic Care Management (CCM) billing codes ${ }^{17}$. For both $\mathrm{CCM}$ and CoCM, results demonstrated the following: (1) a generally positive response to the clinical service; (2) challenges with consent and cost-sharing discussions (albeit not primary or insurmountable ones); (3) concerns about long-term financial sustainability; and (4) difficulties with billing workflow changes, IT interoperability, and time accrual. To date, the impact of CoCM codes on financial sustainability has yet to be assessed empirically, though a recent simulation study suggests that they may provide an opportunity for long-term viability ${ }^{22}$.

We acknowledge several limitations of this study. While reflecting regional diversity, our sample of large, urban, predominately academic organizations does not necessarily reflect the experiences of smaller, non-urban counterparts, nor those of independent primary care practices. Further, the novelty of the CoCM codes provided a relatively short exposure period for organizations and restricted our sample to early adopters (which may be substantially different from later initiators). A majority of the study participants were psychiatrists, which limited our capacity to understand the perspectives of other provider types, administrators, and patients. However, our study did include a number of dually trained (medicine-psychiatry) and internal medicine physicians, as well as diversely trained organizational leaders. Notable strengths of this study include the presentation of viewpoints from both health care organization representatives and payers across a variety of geographic settings, and the inclusion of 
Table 6 Implications of Findings and Proposed Strategies/Solutions for Health Care Organizations

\begin{tabular}{llll}
\hline \hline & & Key findings & Strategies/possible solutions \\
\hline $\begin{array}{lll}\text { Internal and } \\
\text { external contextual } \\
\text { factors }\end{array}$ & $\begin{array}{l}\text { Buy-in from key } \\
\text { stakeholders }\end{array}$ & $\begin{array}{l}\text { Concerns regarding: } \\
\text { • Leadership: Administrative burden and } \\
\text { profitability of CoCM }\end{array}$ & $\begin{array}{l}\text { Engage key members of different stakeholder } \\
\text { groups early in the process and address diverse } \\
\text { concerns associated with implementation of billing }\end{array}$
\end{tabular}

Selection of the CoCM care team

Payer mix and CoCM

reimbursement

\section{CoCM}

components

Patient consent

Time accrual

mechanisms

Electronic health record (EHR) and registry integration or interoperability

Billing/revenue workflow
- Compliance: Proper coding and documentation for CoCM

- Billing/IT: Technological infrastructure for time accrual and code entry

- PCPs: Obtaining consent and discussing cost sharing with patients

- Care managers: Time accrual processes, clinical documentation, and billing code entry

A number of organizations reported preferentially hiring LICSWs for the behavioral health care manager role to allow for the flexibility to bill traditional FFS codes (e.g., psychotherapy) in addition to CoCM codes

Payer mix significantly influences:

- The decision to bill CoCM codes to multiple payers or a single payer (Medicare)

- The decision to bill only CoCM codes versus billing both CoCM and traditional FFS codes

There were notable challenges associated with developing a clear process for consent and obtaining PCP buy-in for this task. Additionally, there was concern that patients had a sub-optimal understanding of cost sharing or the general CoCM service after initial consent

Jointly accruing time spent by multiple team members over the course of a calendar month poses significant challenges

Integration or interoperability of the registry and EHR may save time with documentation or time accrual but can be costly and complex to develop. Although this was considered helpful by study participants, it was not necessary for billing success

Billing once monthly for cumulative patient care time is a major shift in billing workflow that requires careful coordination among multiple clinical and non-clinical staff members. Also, challenges arise because the service is provided jointly by primary care and behavioral health

Financial sustainability
Organizations noted the importance of demonstrating financial sustainability with the CoCM codes, particularly in areas with unfavorable payer mixes for CoCM
A broad range of providers can serve in the behavioral health care manager role for Medicare CoCM billing; it is best to strategically select the appropriate provider type for your organization's reimbursement environment

For an unfavorable payer mix (e.g., few beneficiaries of payers reimbursing for $\mathrm{CoCM}$ ), consider billing CoCM codes for eligible beneficiaries and traditional FFS codes for CoCM services provided to patients of non-reimbursing payers

Possible solutions include:

- Develop scripts and a clear workflow for the consent process

- Create EHR documentation templates to ensure that consent is properly documented each time - Train staff on relevant CoCM billing processes and technologies

Use an adapted spreadsheet specifically for time accrual that is accessible by all CoCM team members, while concurrently exploring options for EHR-registry integration or interoperability Stand-alone registries can be used successfully to support CoCM billing

Possible solutions include:

- A virtual EHR clinic accessible to behavioral health and primary care

- Regular ledger transfers between departments - Primary care directly hiring behavioral health team members

Consider continuously evaluating financial sustainability as the number of regional payers reimbursing for the CoCM codes increases data from billers and non-billers along the Medicare CoCM billing implementation continuum. Finally, this study provides an important glimpse into the experiences of early CoCM code adopters, reveals that "one size fits all" solutions are of limited utility, and describes a range of tailored billing strategies for health care organizations.

Additional research is needed to further assess the experiences of PCPs, behavioral health care managers, and patients with CoCM billing and to measure the service's overall implementation and sustainability costs. Given the immense need for high-quality, evidence-based mental health services nationwide 23,24 , future investigations should examine the broad impacts of these codes on real-world CoCM service delivery and behavioral health clinical outcomes.

\section{CONCLUSIONS}

Although CoCM is an evidence-based and effective model for behavioral health integration, its financing and reimbursement remain significant challenges. The results of this investigation suggest that with deliberate planning, persistence, and widespread organizational buy-in, successful utilization of newly available FFS CoCM billing codes is achievable by health care organizations. 
Contributors: None.

Corresponding Author: Andrew D. Carlo, MD; Department of Psychiatry and Behavioral Sciences University of Washington School of Medicine, Seattle, WA, USA (e-mail: adc42@uw.edu).

Funders Dr. Carlo, the corresponding author, was supported by an NIH-funded post-doctoral fellowship at the University of Washington entitled "Training Geriatric Mental Health Services Researchers" (NIH project number 6T32MHO73553-15).

\section{Compliance with Ethical Standards:}

All interviews were facilitated by a psychiatrist skilled in interviewing techniques and were audio-recorded and professionally transcribed. No honorarium was provided for study participation. This protocol was reviewed and granted exemption by the University of Washington Human Subjects Division (00003585).

Conflict of Interest: Dr. Ratzliff receives royalties from Wiley. All the remaining authors declare that they do not have a conflict of interest.

\section{REFERENCES}

1. AIMS Center - Advancing Integrated Mental Health Solutions. Collaborative Care - Team Structure. https://aims.uw.edu/collaborative-care/ team-structure. Published 2017. Accessed May 23, 2019.

2. Carlo AD, Unützer J, Ratzliff ADH, Cerimele JM. Financing for Collaborative Care-a Narrative Review. Curr Treat Options Psychiatry. July 2018:1-11. doi:https://doi.org/10.1007/s40501-018-0150-4

3. Archer J, Bower P, Gilbody S, et al. Collaborative care for depression and anxiety problems. In: Archer J, ed. Cochrane Database of Systematic Reviews. Chichester, UK: John Wiley \& Sons, Ltd; 2012:2-4. doi:https:// doi.org/10.1002/14651858.CD006525.pub2

4. Cerimele JM, Halperin AC, Spigner C, Ratzliff A, Katon WJ. Collaborative care psychiatrists' views on treating bipolar disorder in primary care: a qualitative study. Gen Hosp Psychiatry. 2015;36(6):575580. doi:https://doi.org/10.1016/j.genhosppsych.2014.07.013

5. Solberg JJ, Deyo-Svendsen ME, Nylander KR, Bruhl EJ, Heredia D, Angstman KB. Collaborative Care Management Associated With Improved Depression Outcomes in Patients With Personality Disorders, Compared to Usual Primary Care. J Prim Care Community Health. 2018;9:215013271877326. doi:https://doi.org/10.1177/ 2150132718773266

6. Fortney JC, Pyne JM, Kimbrell TA, et al. Telemedicine-based collaborative care for posttraumatic stress disorder: A randomized clinical trial. JAMA Psychiatry. 2015;72(1):58-67. doi:https://doi.org/10.1001/ jamapsychiatry.2014.1575

7. Engel CC, Jaycox LH, Freed MC, et al. Centrally Assisted Collaborative Telecare for Posttraumatic Stress Disorder and Depression Among Military Personnel Attending Primary Care: A Randomized Clinical Trial. JAMA Intern Med. 2016;176(7):948. doi:https://doi.org/10.1001/ jamainternmed.2016.2402

8. Engel CC, Bray RM, Jaycox LH, et al. Implementing collaborative primary care for depression and posttraumatic stress disorder: Design and sample for a randomized trial in the U.S. military health system. Contemp Clin Trials. 2014;39(2):310-319. doi:https://doi.org/10.1016/j. cct.2014.10.002

9. Huffman JC, Mastromauro CA, Sowden GL, Wittmann C, Rodman R, Januzzi JL. A collaborative care depression management program for cardiac inpatients: depression characteristics and in-hospital outcomes. Psychosomatics. 2011;52(1):26-33. doi:https://doi.org/10.1016/j.psym. 2010.11.021
10. Woltmann E, Grogan-Kaylor A, Perron B, Georges H, Kilbourne AM Bauer MS. Comparative effectiveness of collaborative chronic care models for mental health conditions across primary, specialty, and behavioral health care settings: Systematic review and meta-analysis. Am J Psychiatry. 2012;169(8):790-804. doi:https://doi.org/10.1176/appi.ajp. 2012.11111616

11. Press MJ, Howe R, Schoenbaum M, et al. Medicare Payment for Behavioral Health Integration. $N$ Engl J Med. 2017;376(5):405-407. doi:https://doi.org/10.1056/NEJMp1614134

12. Centers for Medicare and Medicaid Services. Behavioral Health Integration Services. Medicare Learning Network (MLN). https://www.cms.gov/ Outreach-and-Education/Medicare-Learning-Network-MLN / MLNProducts/Downloads/BehavioralHealthIntegration.pdf. Published 2018. Accessed May 23, 2019.

13. Centers for Medicare \& Medicaid Services (CMS). Medicare Program; Revisions to Payment Policies Under the Physician Fee Schedule and Other Revisions to Part B for CY 2017. Federal Register. https://www. govinfo.gov/content/pkg/FR-2016-11-15/pdf/2016-26668.pdf. Published 2016. Accessed May 23, 2019.

14. AIMS Center - Advancing Integrated Mental Health Solutions. Cheat Sheet on Medicare Payments for Behavioral Health Integration Services. https://aims.uw.edu/sites /default/files/CMS_FinalRule_BHI_ CheatSheet.pdf. Published 2019. Accessed May 23, 2019.

15. Centers for Medicare \& Medicaid Services (CMS). Medicare Program; Revisions to Payment Policies Under the Physician Fee Schedule and Other Revisions to Part B for CY 2018; Medicare Shared Savings Program Requirements; and Medicare Diabetes Prevention Program. Federal Register. https://www.gpo.gov/fdsys/pkg/FR-2017-07-21/pdf/201714639.pdf. Published 2017. Accessed May 23, 2019.

16. Basu S, Phillips RS, Bitton A, Song Z, Landon BE. Medicare chronic care management payments and financial returns to primary care practices: A modeling study. Ann Intern Med. 2015;163(8):580-588. doi:https://doi.org/10.7326/M14-2677

17. O'Malley AS, Sarwar R, Keith R, Balke P, Ma S, McCall N. Provider Experiences with Chronic Care Management (CCM) Services and Fees: A Qualitative Research Study. J Gen Intern Med. 2017;(Ccm). doi:https:// doi.org/10.1007/s11606-017-4134-7

18. University of Washington AIMS Center. AIMS Center - Advancing Integrated Mental Health Solutions. https://aims.uw.edu. Published 2019. Accessed May 23, 2019.

19. Hsieh H-F, Shannon SE. Three Approaches to Qualitative Content Analysis. Qual Health Res. 2005;15(9):1277-1288. doi:https://doi.org/ $10.1177 / 1049732305276687$

20. Miles MB, Huberman AM, Saldana J. Qualitative Data Analysis. 3rd ed. Los Angeles: SAGE PublicationsSage CA: Los Angeles, CA; 2014

21. Centers for Medicare \& Medicaid Services (CMS). Medicare Program: Revisions to Payment Policies Under the Physician Fee Schedule and Other Revisions to Part B for CY 2019. https://www.gpo.gov/fdsys/pkg/ FR-2018-07-27/pdf/2018-14985.pdf. Published 2018. Accessed May 23, 2019.

22. Basu S, Landon BE, Williams JW, Bitton A, Song Z, Phillips RS Behavioral Health Integration into Primary Care: a Microsimulation of Financial Implications for Practices. J Gen Intern Med. 2017;32(12):1330 1341. doi:https://doi.org/10.1007/s11606-017-4177-9

23. Center for Disease Control (CDC). Suicide Rising Across the US. https:// www.cdc.gov/vitalsigns/suicide/index.html. Published 2018. Accessed May 23, 2019.

24. Center for Disease Control (CDC). U.S. Drug Overdose Deaths Continue to Rise; Increase Fueled by Synthetic Opioids. https://www.cdc.gov/ media/releases/2018/p0329-drug-overdose-deaths.html. Published 2018. Accessed May 23, 2019.

Publisher's Note Springer Nature remains neutral with regard to jurisdictional claims in published maps and institutional affiliations. 